\title{
Stylized Facts in the Social Sciences
}

\section{Daniel Hirschman}

Brown University

Abstract: Stylized facts are empirical regularities in search of theoretical, causal explanations. Stylized facts are both positive claims (about what is in the world) and normative claims (about what merits scholarly attention). Much of canonical social science research can be usefully characterized as the production or contestation of stylized facts. Beyond their value as grist for the theoretical mill of social scientists, stylized facts also travel directly into the political arena. Drawing on three recent examples, I show how stylized facts can interact with existing folk causal theories to reconstitute political debates and how tensions in the operationalization of folk concepts drive contention around stylized fact claims.

Keywords: philosophy of social science; politics; knowledge; expertise

- Democracies rarely go to war with each other. ${ }^{1}$

- Countries transitioning to modernity experience a decline in mortality, then a decline in fertility. ${ }^{2}$

- Ten percent of people are gay. ${ }^{3}$

- The share of income going to the top 1 percent in the United States doubled since $1980 .^{4}$

- Nations with debt-to-GDP ratios in excess of 90 percent experience lower GDP growth. ${ }^{5}$

- "Children from same-sex families display no notable disadvantages when compared to children from other family forms." ${ }^{6}$

. Hirschman, Daniel. 2016. "Stylized Facts in the Social Sciences." Sociological Science 3: 604-626.

Received: April 22, 2016

Accepted: April 29, 2016

Published: July 19, 2016

Editor(s): Jesper Sørensen, Sarah Soule

DOI: 10.15195/v3.a26

Copyright: (C) 2016 The Author(s). This open-access article has been published under a Creative Commons Attribution License, which allows unrestricted use, distribution and reproduction, in any form, as long as the original author and source have been credited. (0)(1)
$W^{\text {HAT kind of statements are these? How should we understand them? How }}$ do they circulate within and outside of academia? Here, I argue that these statements-and many others like them across the social sciences-are best understood as "stylized facts." The purpose of this article is to provide a definition for the existing folk concept of stylized fact, to begin to theorize how the production of stylized facts organizes social scientific inquiry, and to trace the circulation of stylized facts beyond the borders of academic inquiry and into the realm of political debates.

Although some social scientists already use the term, stylized facts have thus far received little attention from philosophers and sociologists of social science. Rather, scholars tend to focus on the relatively high-prestige topics of theory choice, theory testing, model building, and so on. Existing work in the philosophy of social sciences has explored in detail the role of mathematical or formal models in the 
social sciences, especially economics, and the study of causal mechanisms, but has paid relatively less attention to the process by which researchers select which facts are worthy of modeling or of mechanistic explanation. Hedstrom and Ylikoski (2010:52) note that mechanistic accounts take as their inputs either the specific facts of a particular case or, when researchers want to produce a more general account, "highly stylized theoretical explananda that do not necessarily have close resemblance to any particular empirical fact" — stylized facts. Likewise, Morgan (2012) notes that economics has become the study of increasingly complex mathematical models. These models are often constructed with the explicit goal of reproducing particular stylized facts.

Similarly, debates over the political power of social science ideas tend to focus on the power of theory, e.g., debates over the power of economics focus on broad paradigms like Keynesianism or neoliberalism (Hall 1989). Stylized facts are not fullfledged explanatory theories. Rather, they are the regularities that social scientists build theories and models in order to explain. And yet, the identification of stylized facts, and consensus or dissensus about the facts identified, can have powerful political consequences even in the absence of causal models.

The identification of a stylized fact is both a normative and a positive claim. Stylized facts are claims about the kinds of things that exist in the world and the patterns of relationships between those things; simultaneously, they are claims about what parts of the social world are worth explaining. Stylized facts thus lie in the messy interstices between theory and description, minimal and maximal interpretation (Reed 2011), fact and value (Putnam 2002; Gorski 2013). And yet, I argue that much, though certainly not all, of "canonical" (Luker 2008) social science research can be usefully understood as the production of stylized facts or debate over the proper stylized facts to characterize social, political, and economic life. ${ }^{7}$ This work of producing and disputing stylized facts merits theorizing as well as empirical analysis by sociologists of knowledge.

In turn, I claim that at least some of the influence of social scientists on public and political debates runs through the production of stylized facts. Social scientists have a privileged position from which to characterize the patterns that make up the social world. For better or worse, these characterizations may circulate beyond the confines of academic discourse into court cases, political platforms, and pundits' talking points. Because stylized facts are often, though not always, stated in terms that are both readily comprehensible to outsiders and highly technical and specific within the context of inquiry, they are especially capable of being (productively) misunderstood. Social scientists frequently measure and theorize constructs outside of their own control, and thus their findings may circulate and do political or cultural work even as they do (potentially very different) academic work.

The remainder of this article proceeds as follows. In section two, I offer an analytical definition of the term "stylized fact." Then, I briefly discuss the term's widespread use in economics and subsequent partial adoption among sociologists. The fourth section argues that stylized facts do some of the same work for canonical social scientists that "phenomena" do for some natural scientists, with the downside that stylized facts come with many fewer guarantees of stability. This section draws on examples from classical as well as contemporary social science. The fifth section 
expands on the claim that the identification of a stylized fact is both a normative and a positive claim and begins to theorize the political role of stylized facts. Finally, I summarize three recent debates over stylized facts that illustrate these various features.

\section{What Is a Stylized Fact?}

This article attempts a dangerous task. "Stylized fact" is a term in widespread use in economics and is increasingly used in other social sciences as well. Thus, in some important sense, this article is an attempt to theorize a "folk" concept, with the relevant folk being social scientists themselves. In this section, I argue that stylized facts should be understood as simple empirical regularities in need of explanation, ${ }^{8}$ and that this definition places stylized facts firmly in the middle of the classical divides between theory and description, minimal and maximal interpretation, and fact and value.

Although thousands of articles explicitly invoke "stylized facts" (see the next section), very few reflect on the term's meanings. An important exception is the first known usage of the term by macroeconomist Nicholas Kaldor. Kaldor coined the term specifically to deal with the problem of generating macroeconomic theory in a world of imprecise macroeconomic observations:

Since facts, as recorded by statisticians, are always subject to numerous snags and qualifications, and for that reason are incapable of being accurately summarized, the theorist, in my view, should be free to start off with a 'stylized' view of the facts-i.e. concentrate on broad tendencies, ignoring individual detail, and proceed on the 'as if' method, i.e. construct a hypothesis that could account for these 'stylized' facts, without necessarily committing himself on the historical accuracy, or sufficiency, of the facts or tendencies thus summarized. (Kaldor 1961:178)

For Kaldor, then, stylizing facts solved the problem of inaccurate or uncertain measurements, freeing the theorist to try to model broad tendencies without accounting for troublesome individual cases. Crucially, Kaldor hoped that economists could agree on a set of basic stylized facts, which could then serve as a benchmark against which to test formal macroeconomic models. I return to the role of stylized facts in model-building in the fourth section.

Kaldor's account of stylized facts is useful, but too narrow, emphasizing only the ways in which stylized facts solve the theorist's problem of imprecise measurement. In this view, in a world with perfect measurement, social scientists would proceed with facts plain and simple, no fancy styles needed. However, many stylized facts in the social sciences emerge to deal with problems other than measurement, including limited attention. Stylized facts serve as competing claims as to the most important, most notable aspects of a given social or economic phenomenon.

Apart from their abstraction from the idiosyncrasies of particular measurements, what makes stylized facts so useful for theoretical and political purposes? Following from the concise definition laid out above ("simple empirical regularities in need of explanation"), I identify four key features of stylized facts. First, stylized facts are necessarily claims about the kinds of things that exist in the world, the categories 
relevant to analysis. They presume or create an analytical ontology. To claim to have identified a regularity is to claim to have identified parts of the world that can be analytically separated and whose movements can be usefully observed. Stylized facts about race, gender, income, war, democracy, nation, and so on assume the relatively stable existence of social kinds worth theorizing about. This is not unique to stylized facts, of course, but it is worth emphasizing. Stylized facts require at least a provisional, bounded, strategic realism.

Second, usually, though not always, these categories are defined in terms a non-specialist can understand. That is, social scientists tend to theorize and analyze with social kinds that are more widespread than their own analysis. Race, gender, income, war, democracy, and nation all have colloquial meanings that inform academic usages but may not completely coincide-in no small part because multiple colloquial and academic meanings often coexist. Producing stylized facts thus requires additional definitional work ("operationalization") on top of the more inchoate definitional work done "out there" in the social world at large. Thus, social scientists transform social kinds into more technical terms by defining precise criteria for inclusion and exclusion. These terms are often associated with particular operationalizations connected to particular datasets. For example, "race" to a sociologist using the Current Population Survey means something very concrete in practice; its complexities (although known to researchers) must be strategically bracketed to produce knowledge about large-scale movements of populations over time. And yet, technical definitions do not exist in isolation from fuzzier definitions used outside of research, and this potential for conflation contributes to the capacity of stylized facts to travel beyond the narrow confines of academic debates.

Third, stylized facts are typically understood as claims of non-robust dependence. In his summary review of understandings of causality in sociology, Goldthorpe (2001) identifies "robust dependence" as one key mode of causal reasoning (see Hirschman and Reed [2014] for a lengthy discussion). $X$ is a cause of $Y$ if we find an association between $X$ and $Y$, and that correlation persists after accounting for all the plausible intervening causes ("controlling" for possible confounding variables). Stylized facts, though sometimes identified through statistical techniques associated with the robust dependence paradigm (including regression analysis and its variants) are not causal claims. Rather, stylized facts are typically simple associations that have yet to be "explained," either through more complicated analysis in the style of robust dependence, or through some appeal to underlying mechanisms, or through some inferential technique relying on experimental or quasi-experimental manipulations. That is, a stylized fact is a claim that $X$ is associated with $Y$, but the claim is explicitly agnostic as to why $X$ is associated with $Y$. Instead, stylized facts are "looking" for explanations; that is, they are calls to other social scientists to hunt for causal explanations.

This characterization of stylized fact as claims of non-robust dependence is particularly obvious in stylized facts that take the form of associations or correlations. For example, and as discussed at length below, Reinhart and Rogoff (2010) claimed to find an association between high debt and low GDP growth. Stylized facts can also take the form of rates of incidence or trends. Trends can be understood as non-robust dependence on time- that is, of a correlation between some variable and 
time, such as the increasing share of financial profits in the late twentieth century American economy (Krippner 2011). Rates of incidence, on the other hand, are claims about the lack of an association with time, that is, that a particular event or kind of person maintains a relatively stable rate of occurrence, such as the Kinseyinspired claim that ten percent of people are gay. Associations, incidence, and trends are all usefully understood as stylized facts, and I do not dwell on the differences between them here, nor do I claim that they exhaust the space of stylized facts.

Fourth, and finally, stylized facts, either implicitly or explicitly, serve as normative claims that the particular regularities identified are the ones most important to study and are preferable to other potential characterizations of the evidence. As an example, claims about the "financialization" of the American economy explicitly argue that financialization is a better characterization of trends in the late twentieth century than earlier attempts, such as "post-industrial" (or at least, that earlier characterizations were insufficient [Krippner 2011]). This normative claim can do political as well as theoretical work; this political dimension will be explored further below.

Together, these four features place stylized facts in an awkward location from the standpoint of philosophy of (social) science. Stylized facts are not full-blown explanations or theories, nor are they simple reports of a set of specific facts. Rather, they are lightly theorized descriptions - theories of what is and what is worth noticing. In Abend's (2008:178) typology, stylized facts are a form of "Theory 3 ": "What theories 3 offer is an original 'interpretation,' 'reading,' or 'way of making sense' of a certain slice of the empirical world. They may shed new light on an empirical problem, help one understand some social process, or reveal what 'really' went on in a certain conjuncture." Abend associates this sort of theory with hermeneutics and argues that such theories are rare in U.S. sociology (Abend 2008:179). I argue that stylized facts are quite pervasive, but often misrecognized as just descriptive, and thus not explicitly treated as theories. Much as the theoretical work involved in producing data is ignored or downplayed (Edwards 2010), so is the theoretical work of abstracting one level up from that data to identify patterns. For many social scientists, the "real" theoretical work begins at the next stage with the production of models or the identification of mechanisms to explain the identified patterns.

Similarly, stylized facts fall solidly in the middle of Isaac Reed's distinction between "minimal" and "maximal" interpretation (Reed 2008, 2011). Minimal interpretations are the uncontroversial, or relatively uncontroversial, first steps involved in making sense of "what happened" in a particular case or facet of the social world. Reed recognizes that such work is an act of interpretation (as are all attempts to describe the world), but emphasizes how-even in controversial cases-the minimal interpretation of events may be widely agreed-upon: "just think of the French revolution-we know what happened on the night of 4 August 1789, and the night after that, and the year after that, and so on." (Reed 2008:196) At the other extreme, maximal interpretations-fully theorized explanations of an event-are often controversial and go far beyond the data. In between is much of the work of social science, including the production of stylized facts. Stylized facts are not mere descriptions of findings, but rather selected regularities identified 
as especially worthy of investigation. Thus, stylized facts are one of the many potential middle grounds between minimal and maximal interpretation, one linked to "canonical" social science (Luker 2008) that emphasizes thinking in terms of regularities, generalizability, representation, and populations.

Stylized facts are also an excellent example of the untenability of the fact-value dichotomy (Putnam 2002). Specifically, in claiming that a certain aspect of the world merits explanatory work, stylized facts place a claim on what matters, what is important to pay attention to, to measure; in a word, what academics should value.

\section{Explicitly Stylized Facts in Economics and Sociology}

As mentioned above, the explicit invocation of stylized facts began with the economist Kaldor writing in the early 1960s about macroeconomics and growth. Since Kaldor's work, the phrase has taken off (see Figure 1). ${ }^{9}$ In this section, I briefly characterize the explicit use of stylized facts in economics and sociology. These explicit invocations are just a subset of the full extent of the use of stylized facts, however. As we will see, in sociology, the term has only recently caught on, and even then, primarily in those subfields most closely connected to economics.

Of the 6,299 articles mentioning stylized facts in JStor ${ }^{10}, 5,110$ (about 80 percent of all mentions) come from economics journals. These comprise more than 1 percent of all economics articles in the database. ${ }^{11}$ In contrast, just 193 sociology articles use the term, comprising less than 0.1 percent of all sociology articles. ${ }^{12}$

Early mentions in economics are dominated by discussions of the "Kaldor Facts"- a set of six macroeconomic regularities observed by Kaldor in an earlier paper (Kaldor 1957) and introduced as explicit stylized facts in 1961. Most famously, Kaldor noted that the shares of national income received by labor and capital remained relatively constant over long periods of time. From there, the term spread. In the 1970s, we see references in other subfields, for example, "Income Distribution and Development: Some Stylized Facts" (Ahluwalia 1976). Stylized facts fit the logic of inquiry in economics quite closely: using newly available macroeconomic datasets, empirical research identified important regularities in the economy, which theorists could then attempt to explain through the construction of formal models.

Stylized facts only entered explicitly into sociology more recently. Tellingly, the earliest uses in sociology journals centered around economic topics: income inequality, salary discrimination, and the like, including several articles whose only mention was a cite to Ahluwalia's (1976) stylized facts on income inequality and development, mentioned above. Some articles were even authored by economists in sociology journals, (e.g., Milgrom and Roberts [1988]) "An Economic Approach to Influence Activities in Organizations" in the American Journal of Sociology).

In the 1990s and 2000s, more sociologists begin invoking the term themselves, but still often in economic contexts. Morris and Western's (1999) review article on income inequality offers a nice example of sociologists invoking stylized facts in an economic context:

The next question for most sociologists is how the trends in earnings breakdown by race. The stylized facts are that the decline in the race gap in income that had begun in the 1960s came to a halt in the early 


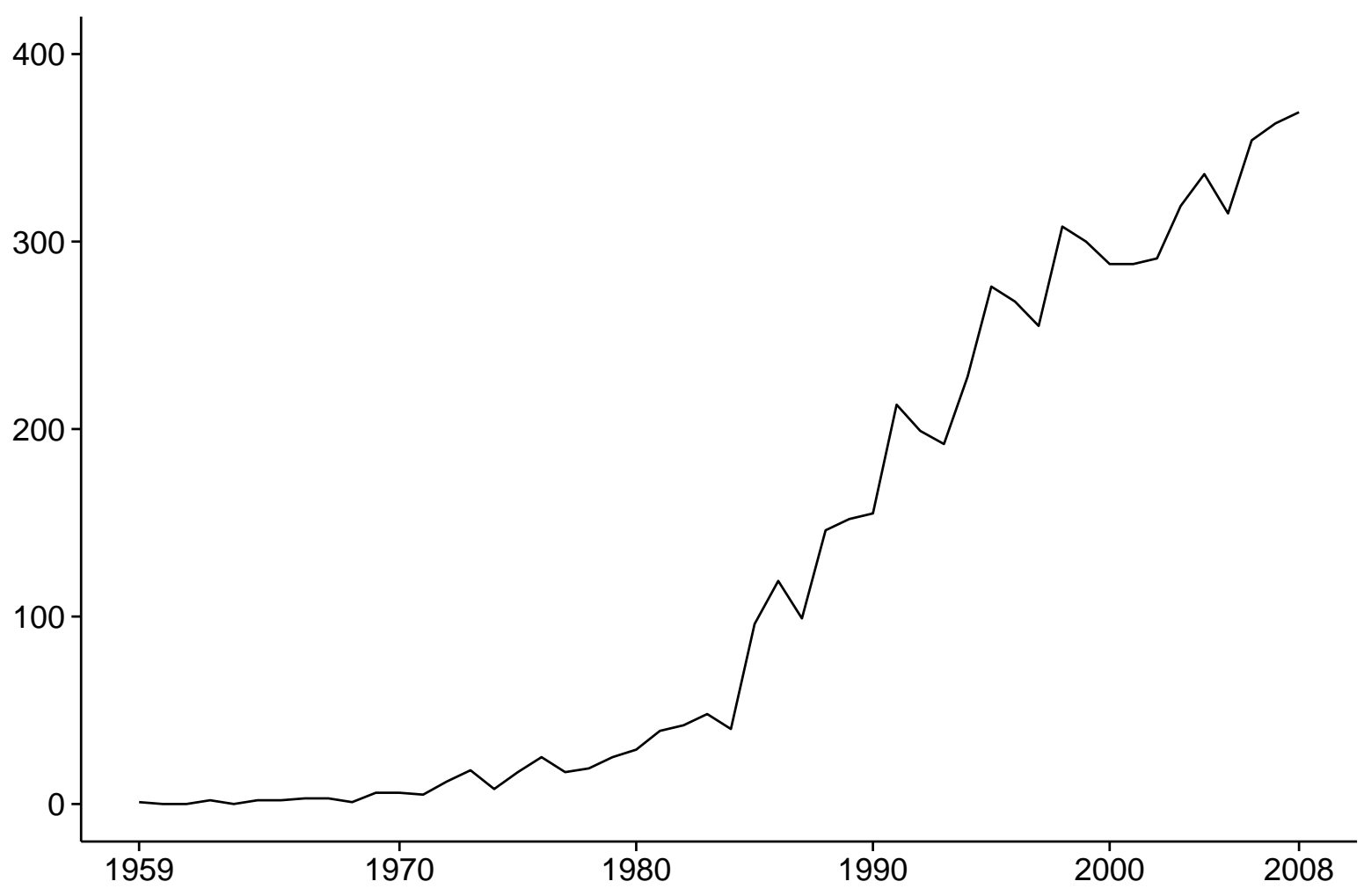

Figure 1: Count of all articles (including research articles as well as book reviews, notes, etc.) in JStor containing the term Stylized (or Stylised) Fact (or Facts) by year, 1959-2008. Total N=6,299. Source: JStor Data For Research.

1970s... and reversed by the mid-1970s, leaving blacks in the early 1990s at about the levels they had been in the late 1970s.

Here, stylized fact is a lightly abstracted version of an important trend. Other examples include Tienda et al.'s (1992:365) analysis of post-war labor force participation: "Although the sharp rise in women's labor force activity rates during the post-World War II period is well known, more stylized facts about differential rates of increase among racial and ethnic groups are less systematically documented." Here, interestingly, we see a reference to "more" stylized facts, which are simply those that have one extra layer of complexity and refinement (trends broken down by gender and race, not just gender). All of these explicit usages, in both economics and sociology, correspond well with the analytical definition proposed here: simple empirical regularities looking for explanations.

Of course, the slow diffusion of the explicit invocation of stylized facts should not mislead us. Sociologists have long drawn on stylized facts under other names. In the following section, I argue that stylized facts take the place of phenomena for many sociological investigations, going as far back as the work of Emile Durkheim and Max Weber. 


\section{Stylized Facts as the Phenomena of Social Science}

What do stylized facts do for social scientists? Why do we bother finding them and fighting over them? Here, I argue that stylized facts serve, for a subset of social science, as a substitute for phenomena. This extends Kaldor's claim that stylized facts are necessary because they abstract away from the vagaries of measurement error and temporary perturbations. This abstraction is necessary to give canonical sociological and economic theories-meaning here both formal, mathematical theory and models and more literary modes of theorizing-something about which to theorize. Echoing Leifer (1992), stylized facts insulate higher-order theories from the idiosyncrasies of data. Unfortunately, in the social sciences, not just our causal explanations, but also our lightly theorized empirical regularities are happy fictions, with few guarantees of long-term stability.

In his introduction to the philosophy of science Representing and Intervening, Ian Hacking (1983) argues that most accounts of the success of science have overstated the success of science as a mode of representation while underappreciating its success at reliable intervention. For Hacking, a phenomenon is "an event or process of a certain type that occurs regularly under definite circumstances" and which is "noteworthy" and "discernible" (Hacking 1983:222). The secret to progress in the natural sciences, Hacking argues, is in its ability to produce novel phenomena. We can think here of something like the photoelectric effect: if you shine the right kind of light on the right kind of material, a current is generated. The meaning of this phenomenon-how it was represented in scientific theories-has changed over time. But the effect itself, the phenomenon, persists. And indeed, it is the production of new and unexpected phenomena that, in some models of natural science, produces radical shifts in scientific theories (Kuhn 1969).

Stylized facts bear a passing similarity to Hacking's phenomena. Both emphasize observable regularities, and neither makes strong claims to theoretical or causal explanation. Both are inputs to the process of theorizing. And yet, stylized facts differ from phenomena in several key respects. First, phenomena are generally produced through intervention. The scientist is assumed to stand outside the system being observed and, through various technical pokings and proddings, elicits a response from the system. Although natural scientists cannot always explain a phenomenon in terms of a more general theory, they can explain it in terms of their own actions-shine the light, current; turn off the light, no current. Social scientistsespecially outside of psychology, which more frequently relies on experimental methods-rarely have the luxury of standing outside and manipulating a social system. ${ }^{13}$

Second, and even worse, social scientific stylized facts are usually cast in terms of social kinds. As Hacking has noted in his later work, social kinds are interactive or reactive-they are capable of changing in response to the knowledge generated about them (Hacking 2000:108; Hacking 2007). Hacking terms this process "dynamic nominalism," the process by which naming (making knowledge about) something can change the thing named (Hacking 2000). Social scientists want to produce stylized facts about race, gender, income, occupation, sexuality, nationality, and all the other social kinds that populate both academic and popular discourse. Facts 
about these social kinds are the sort likely to be of interest to social scientists and policymakers. Unfortunately for researchers, social kinds are not stable, and academic research may participate in the instability of these kinds (Hirschman and Reed 2014). And, of course, academic investigations are not the only source of change in social kinds-social change has many origins. Stylized facts are thus generalizations about moving targets.

Thus, rather than advancing through the successive production and explanation of new phenomena, canonical social science marks advancement through the identification and theorization of new stylized facts. That is, researchers isolate certain empirical pseudo-regularities and then construct theories or formal models to explain why these regularities tend to occur. Stylized facts, unlike phenomena, are assumed to be somewhat unstable-go far enough back in time, or experience enough societal upheaval, and the facts may change-but are hoped to be stable enough to serve as grist for the theoretical mill.

Two classic examples might be helpful at this point. In Suicide, Durkheim (1997) identifies certain trends in the relationship between suicide and various kinds of events or social conditions. For example, suicide rates are higher among Protestants than Catholic, among men than women, and among single people than married people. Durkheim then theorizes why these rates take the form they do in his classic typology of suicides and discussion of anomie. Note that the specific rates are relatively unimportant to the argument and that peculiarities and outliers are beside the point. The goal, for better or for worse, was to explain the simple empirical regularities that Durkheim identified as important.

Lest we too quickly associate stylized facts solely with the positivistic side of sociology, let's turn to Max Weber's The Protestant Ethic and the Spirit of Capitalism. Like Durkheim, Weber begins with the observation of a stylized fact about religion and occupation:

A glance at the occupational statistics of any country of mixed religious composition brings to light with remarkable frequency a situation which has several times provoked discussion in the Catholic press and literature, and in Catholic congresses in Germany, namely, the fact that business leaders and owners of capital, as well as the higher grades of skilled labor, and even more the higher technically and commercially trained personnel of modern enterprises, are overwhelmingly Protestant.

(Weber 2001:3)

Weber does not directly explain this contemporary finding, but uses it to motivate an historical inquiry: "There arises thus the historical question: why were the districts of highest economic development at the same time particularly favorable to a revolution in the Church?" (2001:4) From here, Weber develops his famous thesis about the protestant ethic and its elective affinity with capitalism. No need to belabor the point: stylized facts have long been ingredients of sociological (and economic) theorizing, even if the term itself is of a more recent vintage. The three examples below offer more detailed, contemporary accounts of the relationship between stylized facts and social scientific theorizing. 


\section{Stylized Facts as Normative Claims}

Stylized facts are certainly positive claims; that is, claims about what exists in the world. Here, I argue that stylized facts are also normative or value-laden claims. This value-laden character of stylized facts flows from three sources. The first, identified by Hilary Putnam, is common to all factual claims. The second is related, but somewhat different, and follows from the limited capacity of scholars, politicians, and everyone else to attend to every aspect of the world. The third involves much more overt politics and the interactions of careful academic claims and everyday causal reasoning.

In "The Collapse of the Fact/Value Dichotomy," Hilary Putnam argues that the tidy distinction between facts and values does not withstand close scrutiny. This distinction has a long history (Putnam 2002:14; Gorski 2013), merging with the similar separations between "positive" and "normative" claims and statements of "is" versus "ought." In the mid-twentieth century, the fact/value dichotomy was muddied by the collapsing separation between facts and theories. Quine argued that statements of facts and the analytical "conventions" needed to make those statements were inseparably entangled (Putnam 2002:29-30), or, as Kuhn would put it, data are theory-laden (Kuhn 1969). Putnam argued that because facts and analytical conventions (theories) are hopelessly entangled, facts too become entangled with a very specific kind of value-epistemic values.

Epistemic values encompass conventions or norms about what makes for good knowledge. For instance, in various disciplines, parsimony (or simplicity) is considered a virtue (Putnam 2002:31). Comparing two models that perform similarly on other metrics (say, predictive power), the more parsimonious model is deemed superior. Why? Scholars may offer reasons for preferring parsimony, but the preference for parsimony still constitutes a kind of epistemic value.

What does this have to do with stylized facts? Like other factual claims, stylized facts imply certain epistemic values. When we claim that financialization instead of post-industrial is the best way to think about the contemporary American economy, we offer (explicitly or implicitly) some justifications for why that stylized fact better captures the current situation. These justifications are rooted in Putnam's epistemic values.

But, and here we move beyond Putnam, stylized facts are more explicitly normative claims. Stylized facts are not simply claims about what is in the world, but also claims about what merits sociological attention. A diverse group of scholars across fields has pointed out how our collective capacity—organizational, academic, or political - to pay attention to problems is limited (March and Simon 1958; Bendor 2003; Kingdon 2002; Proctor and Schiebinger 2008; Elliott 2013). The "attention space" or "agenda" can only contain so many items. Thus, to claim that a particular stylized fact needs to be explained implies that other possible characterizations will simply be ignored. As will be discussed below, if we think of inequality in terms of differential returns to education, we may miss growing inequality within the set of highly educated individuals.

Finally, as discussed above, stylized facts do not themselves carry any causal claims. That said, they enter into an academic and political context replete with 
its own understandings of causality, which may or may not have much basis in academic research. Stone (1989) refers to these folk causal narratives as "causal stories" and documents their influence on policymaking. Thus, an expert's claim to have identified, but not explained, an empirical regularity may meet up with another expert theory or non-expert causal story and serve as support for it.

For example, the claim that the children of same-sex parents have dissimilar, and more negative, outcomes from the children of other family forms does not itself imply any particular policy about same-sex adoption or marriage. But, when combined with an everyday causal theory that posit same-sex parents as inferior, the stylized fact is taken up as evidence for the theory and its attendant policies, and the scholar-intentionally or otherwise-becomes enrolled in a network advocating a particular outcome. The concrete examples in the next section further illuminate this point.

\section{Three Examples}

This section explores three examples from the large space of stylized facts. These facts were chosen somewhat capriciously and are not claimed as "representative" of the set of stylized facts. Rather, due to their high profile and connection to political controversies, they are seen as particularly strategic, rich sites for thinking through the connections between stylized facts, social scientific theorizing, and policymaking.

\section{Top Incomes in the United States}

Mainstream social science in the twentieth century United States paid little attention to the overall distribution of personal income. ${ }^{14}$ Macroeconomists focused their attention on other variables-GDP, unemployment, and inflation-leaving little room for concerns with income inequality (Atkinson 1997). Data on income distribution are not included in the US National Income and Product Accounts, for example, or the United Nation's similar System of National Accounts. Labor economists studied inequality, but their emphasis was on gaps between meaningful groups within the neoclassical theoretical framework that links differences in wages to differences in productivity rather than on changes in the overall distribution. Thus, the big disputes in labor economics have concerned the role of unions and, in the 1980s, the increasing returns to a college degree. Similarly, sociologists have largely studied gender and racial gaps, along with educational ones (Morris and Western 1999; Hout 2012).

These studies established a collection of stylized facts about inequality in the late twentieth century: the growing gap between college and non-college educated workers, the decreasing then increasing gap between blacks and whites, and the closing but by no means closed gap between men and women (Morris and Western 1999). Sociologists and economists debated the significance of these stylized facts and the best ways to characterize them.

In the early 2000s, two economists, Piketty and Saez (2003), proposed a new stylized fact as an alternative way to characterize income inequality. Piketty and 
Saez, drawing on previously ignored tax data, showed that the share of income going to the top income earners-the top $1 \%, .1 \%$, and $.01 \%$ of tax units-had increased dramatically in the 1980s, back up to levels not seen since the Great Depression. Labor economists and sociologists had largely ignored these data because they were incapable of telling who was inhabiting the top $1 \%$-whether they were college-educated or not; whether they were professionals like doctors and lawyers, or business owners and CEOs; men or women; black or white. Instead, scholars had relied on data from surveys (e.g., the Current Population Survey), which top-coded incomes and thus were unable to track movements within the top few percent. Piketty and Saez's alternative characterization supplemented existing accounts and made sense of previously idiosyncratic narratives, like the tremendous increase in CEO compensation. Inequality was not (just) a matter of highly skilled college grads outcompeting blue-collar workers but also about the very elite somehow soaking up more money.

Of course, not all economists agreed with Piketty and Saez's findings. Reynolds (2007), Burkhauser (2011), and others have argued that the observed dramatic increase in top incomes in tax data is an artifact of changes in tax law, among other things, that led to a shift in how the well-off reported their income, but not a major shift in the actual distribution of income. These researchers also dispute Piketty and Saez's unit of analysis ("tax-units" being a strange in-between of the traditional units of households or individuals) and definition of income (necessarily limited to what is reported to the IRS). The debate rages on. For the moment, though, the fact of the $1 \%$ seems to have survived initial scrutiny and traveled out into the academic and political world.

Note that Piketty and Saez did not initially claim to explain why this growth in top incomes occurred. But their narrative clearly begged for such an explanation. Paul Krugman (2002), writing in The New York Times Magazine, offered such an attempt before the final version of the paper was even published. Krugman argued that scholars needed to take into account politics to explain movements in top incomes-traditional economic explanation based on productivity simply could not explain such a dramatic movement. Political scientists and sociologists, along with economists, have since worked on just such explanations. Perhaps most prominently, Hacker and Pierson (2010) traced the shifting political coalitions that led to a "winner-take-all politics" and, in turn, growing top incomes. A new stylized fact led to new theories.

At the same time, the fact of growing inequality at the very top had political ramifications as well. Apart from the obvious connection to debates over tax policyfor example, President Barack Obama's proposals to increase taxes only for very high income earners resonated strongly with the finding that such incomes had increased dramatically- "the $1 \%$ " and its mathematical complement, the " $99 \%$ " have entered into our lexicon alongside more traditional interest groups. The widespread, if short-lived, Occupy Wall Street movement went so far as to turn "We are the 99\%" into a mobilizing slogan. Here then, we also see a new stylized fact help to constitute a social movement's identity. 


\section{The 90\% Debt/GDP Threshold that Wasn't}

In 2007-2008, the United States experienced a major financial crisis. Soon, much of Europe followed. Government deficits rose dramatically as social welfare expenditures increased (more unemployed people applying for benefits) and revenues declined (fewer people working means fewer people paying taxes). As the immediate crisis passed and unemployment remained high, governments debated the appropriate response. Many economists-including presidential advisors like Christina Romer and Larry Summers, as well as public intellectuals like Paul Krugman and Brad DeLong - argued for a return to the playbook written in the aftermath of the Great Depression: sustained levels of high government expenditures to employ the unemployed, prime the pump, and stimulate short-run spending to get the economy back to its potential.

One of the major counterarguments to this position came from economists and conservative politicians worried about the effects of increased government debt on economic growth (see Blyth 2013 for the history of this argument). In 2010, Harvard economists Carmen Reinhart and Kenneth Rogoff published a paper in the American Economic Review's "Papers + Proceedings" issue (a non-peer reviewed collection of short papers from the annual meetings of the American Economics Association) that became instant ammunition for the austerity argument. Reinhart and Rogoff had become prominent with the publication of their 2009 book, This Time is Different, which systematically showed that economies recovered slowly from recessions brought on by financial crises as compared to other recessions. In their new paper, "Growth in a Time of Debt," Reinhart and Rogoff (2010, R\&R hereafter) identified a stylized fact about the relationship between growth and debt: "Our main result is that whereas the link between growth and debt seems relatively weak at 'normal' debt levels, median growth rates for countries with public debt over roughly 90 percent of GDP are about one percent lower than otherwise; average (mean) growth rates are several percent lower" (R\&R:573). It was this last findinga dramatic "threshold" (R\&R:575) where growth declines if debt is higher than $90 \%$ of GDP - that caught the attention of policymakers looking to justify austerity measures.

In the published paper, $R \& R$ were careful to avoid making causal claims. The $90 \%$ threshold was a classic stylized fact: a potentially important association that merited further exploration. In their public advocacy, however, R\&R were much less circumspect. For example, a 2011 editorial in Bloomberg View translated the associational claim into a causal one, stated baldly in the title: "Too Much Debt Means the Economy Can't Grow." Mobilizing their 2010 paper, R\&R went on to assert:

[B]urdens above 90 percent are associated with 1 percent lower median growth. Our results are based on a data set of public debt covering 44 countries for up to 200 years. The annual data set incorporates more than 3,700 observations spanning a wide range of political and historical circumstances, legal structures and monetary regimes.

We aren't suggesting there is a bright red line at 90 percent; our results don't imply that 89 percent is a safe debt level, or that 91 percent is necessarily catastrophic. Anyone familiar with doing empirical research 
understands that vulnerability to crises and anemic growth seldom depends on a single factor such as public debt. (Reinhart and Rogoff 2011)

The last paragraph offers an interesting caveat, much along the lines of Kaldor's original understanding of stylized fact. $R \& R$ assert an association, but note that there is some likely measurement error or blurriness in the finding. The slide from correlation to causation repeats itself: paragraph one, just association; paragraph two, implying that a $90 \%$ debt level might be "catastrophic," i.e., causally related to growth and very harmful to it. $R \& R$ went on to make similar statements in other venues, including meetings with influential policymakers (Fernholz 2013). Many countries cut back on spending, justified (in part) by the need to rein in growing debts, though not necessarily because of R\&R's influence. Proving that policy advice had a strong effect is notoriously difficult; at a minimum we can say that R\&R had the ear of influential people and that some of their words influenced the rhetoric of those influential people.

As R\&R's work circulated politically, and as several European countries chose the path of austerity, academics took a closer look at the basic stylized fact $R \& R$ claimed to have discovered. Scholars initially had trouble replicating R\&R's finding, and the published material did not make it clear how they had weighted different countries, among other things. In 2013, the story took an unexpected turn. R\&R shared their spreadsheet with an economics graduate student from the University of Massachusetts-Amherst, Thomas Herndon. Herndon, with two of his advisors, published a working paper documenting one obvious flaw in the calculation, along with several questionable choices (Herndon et al. 2013). R\&R had weighted every country's experience of high debt equally, whether the country experienced high debt for one year or seventeen. This choice, while plausible for some purposes, was controversial. Adjusting for these factors, Herndon et al. found no relationship between debt/GDP and later growth:

The influence of RR's findings comes from its straightforward, intuitive use of data to construct a stylized fact characterizing the relationship between public debt and GDP growth for a range of national economies. However, this laudable effort at clarity notwithstanding, RR has made significant errors in reaching the conclusion that countries facing public debt to GDP ratios above 90 percent will experience a major decline in GDP growth.... The full extent of those errors transforms the reality of modestly diminished average GDP growth rates for countries carrying high levels of public debt into a false image that high public debt ratios inevitably entail sharp declines in GDP growth. (Herndon et al. 2013:14)

Subsequent research using R\&R's data suggests some more complicated relationships, but none of which imply any kind of sharp threshold or strongly negative relationship around 90\% debt/GDP, and some of which even imply that future growth benefits from high debt, whereas current low growth is the cause of later high debt (Dube 2013; Kimball and Wang 2013). Although academics had always disputed the causal relationship assumed by policymakers-and R\&R in their policy advocacy - the ability to undermine the stylized fact presented by R\&R was deemed to be a major blow to the argument. Time will tell how much difference it 
makes. For now, the effects of the 2010-2012's turn to austerity are still being felt, perhaps in small part due the circulation of R\&R's stylized fact.

\section{"No Differences" for Children from Same-Sex Families}

This is a tale of two competing and directly opposed stylized facts. In June 2013, the United States Supreme Court simultaneously issued two rulings related to same-sex marriage. One ruled unconstitutional the Federal Defense of Marriage Act (DOMA), forcing the federal government to grant benefits to married same-sex couples. In the other, Hollingsworth $v$. Perry, the Court dismissed a challenge to a district-court ruling that overturned California's Proposition 8, which banned samesex marriage. One aspect of the case, although not one that eventually factored into the legal justification for dismissing the challenge, hinged on the possible reasons why Californians voted for banning same-sex marriage. Was there a rational basis for the ban? The District Court ruled that there was not. At the Supreme Court level, a possible reason was presented: the children of same-sex parents do worse on various outcomes of interest than children of opposite-sex parents.

The argument hinged on a recently published study that compared children of same-sex parents authored by sociologist Mark Regnerus (2012) "How different are the adult children of parents who have same-sex relationships? Findings from the New Family Structures Study." The paper and its findings have since been subject to a great deal of controversy, including allegations that the review process at Social Science Research was tainted (as one or more reviewers may have been consultants on the study) and that conservative funders may have exercised undue influence over the design of the study and the reports of its findings, in addition to the more common allegations that, as in the case of Reinhart and Rogoff, Regenerus' definitions and analytical choices were misleading (Perrin et al. 2013). ${ }^{15}$

At its core, Regnerus (2012) offers a clear example of the contestation of an existing stylized fact. Regnerus begins with the claim that existing research has been too flawed, largely because of a lack of random samples, to support the so-called "no differences" paradigm: "that children from same-sex families display no notable disadvantages when compared to children from other family forms." (Regnerus 2012:753) This paradigm is, itself, a stylized fact-a simple empirical regularityand not a causal explanation. Regnerus (2012) puts forward the logical complement, that children from same-sex families display some notable disadvantages:

When compared with children who grew up in biologically (still) intact, mother-father families, the children of women who reported a same-sex relationship look markedly different on numerous outcomes, including many that are obviously suboptimal (such as education, depression, employment status, or marijuana use).

The purpose of Regnerus (2012), then, is to advance a competing and contradictory stylized fact to the "no differences" one-call it "some suboptimal differences."

Like many papers aimed primarily at advancing a new stylized fact (and, in this case, contesting an existing one), Regnerus (2012) is careful to avoid strong causal claims and to avoid too many direct policy implications. The observed association might have many possible causes: 
Although the findings reported herein may be explicable in part by a variety of forces uniquely problematic for child development in lesbian and gay families-including a lack of social support for parents, stress exposure resulting from persistent stigma, and modest or absent legal security for their parental and romantic relationship statuses... (Regnerus 2012:766)

The point, however, is to replace an old stylized fact with a new one: "the empirical claim that no notable differences exist must go." (Regnerus 2012:766) And yet, as we know from the case history, Regnerus' paper was cited instantly as evidence for the rationality of California voters: if the children of same-sex parents have some negative outcomes, it is rational for the voters of California to want to discourage same-sex unions because of some assumed, but unstated, causal link.

Almost immediately, Regnerus (2012) and its citation by opponents of same-sex marriage drew intense criticism from other academics. Chief among the criticisms of Regnerus' paper was the operationalization of the key independent variables: "gay father" and "lesbian mother." These terms, which seem commonplace enough, take on a specific technical operationalization in Regnerus' study (as they must in any study). For Regnerus, respondents are coded as having a gay father or lesbian mother if they report that parent ever having a same-sex relationship. This coding captures individuals who grew up their entire lives in households headed by a same-sex parent but also individuals who never lived with same-sex parents. These coding choices, along with comparisons primarily to "intact biological families," which definitionally did not experience divorce or other negative outcomes, led one prominent critic to label the paper "bad science not about same-sex parenting."16

Following the critiques, the consensus among sociologists favored the "no differences" paradigm and rejected Regnerus' findings. The American Sociological Association went so far as to issue an amicus curie brief reaffirming that sociology's consensus position was the "no differences" one. ${ }^{17}$ These debates all centered on the right stylized fact to characterize the outcomes of different family forms. The political consequences of those stylized facts were presumed in advance, in spite of all sides agreeing that the observed relations were associations and not causal, and that the same findings could support different policy recommendations. For example, Osborne (2012:783) noted that the observed negative relationship between having same-sex parents and negative outcomes (if real) could be entirely accounted for by legal discrimination against same-sex parents: "For all we know, the effect derives entirely from the stigma attached to such relationships and to the legal prohibitions that prevent same-sex couples from entering and maintaining 'normal' marital relationships." Such a causal story would turn evidence of negative outcomes into an argument for legalizing same-sex marriage. But rather than argue causality, the public debate turned on the stylized fact itself.

Regnerus, constrained somewhat by his reviewers and editor, had control over the terminology of the findings. Without some specialized skills, outside readers would not be able to assess the quality of the link between the political commonplace "gays and lesbians" or "gay and lesbian parents" or "gay and lesbian families" and the family structures specified in Regnerus' study. Regnerus' study actually investigates a group that is not socially or politically meaningful "young adult 
children of parents who have had a same-sex relationship." But Regnerus reports his findings in terms that are filled with political salience: children of same-sex parents, or children of lesbian mothers and gay fathers. An attentive reader with access to the full article and some understanding of how to read a methods section can decide on their own whether or not the statistical category in the data corresponds to the salient, socially recognized, politically meaningful category. But in attempting to forge that link, Regnerus converts his findings into ones more directly relevant to the political debate and, thus, more capable of answering political or legal questions, including the permissibility of same-sex marriage and adoption. The conclusion is especially telling:

While previous studies suggest that children in planned GLB families seem to fare comparatively well, their actual representativeness among all GLB families in the US may be more modest than research based on convenience samples has presumed. (Regnerus 2012:766)

Note here that Regnerus himself is offering a redefinition of the politically salient category of gay and lesbian families. It is quite possible that advocates for GLB families would not draw the boundaries of the category in the same fashion of Regnerus. And, significantly, advocates of same-sex marriage (who Regnerus references elsewhere in the conclusion, noting that courts are increasingly legalizing same-sex marriage) may explicitly have in mind stable, intact, two-parent units who plan their families, not Regnerus' definitions, which count as a GLB family any case where either parent had any same-sex relationship. Neither definition is wrong-definitions, in some sense, are incapable of being wrong in their own context. But findings do not stay within the confines of a single paper or study. Facts "travel," in Mary Morgan's felicitous phrase (2010). And when social scientists subtly redefine a category (and in some sense, they are incapable of doing otherwise, as the socially recognized category rarely maps perfectly onto the categories available in a dataset and is likely too fuzzy and contested for any single definition to accurately characterize everyone's understanding) and then make claims about stylized facts characterizing that category, they are engaging in an important kind of politics.

These three examples tell quite different stories. All involve the production and circulation of a seeming empirical regularity that called out for more academic research, but that also had immediate political salience in its unexplained form. In all three stories, other scholars hotly contested the stylized facts. So far, some have stood up ("no differences," "growth of the top 1\%") to academic scrutiny, while others have fallen and been replaced ("some suboptimal differences," "90\% Debt/GDP threshold"). Each led to, or was part of, an intense political mobilization-in spite of, or even because of, their lack of causal claims. Other examples would have illustrated different points, of course-for example, the Kaldor facts themselves spawned a long line of macroeconomic modeling as well as empirical work challenging some of the stability assumptions (Elsby et al. 2013). The examples chosen here simply demonstrate some of the possible ways that stylized facts may circulate within and between academics, policymakers, and the public. 


\section{Conclusion and Future Directions}

Stylized facts are pervasive features of contemporary canonical social scientific research. Lacking stable phenomena produced through intervention, and blessed and cursed to theorize in terms outside their complete control, social scientists proceed by the identification of simple empirical regularities and the selection of some of those regularities for further research. These stylized fact claims are one part theory and two parts description, "medium" interpretations, facts with a dose of values. And yet, in spite of their precariousness, stylized facts are seen as capable of undergirding influential social scientific theories.

Following the identification of a stylized fact, there are three logical next steps for social scientists. First, social scientists may accept the stylized fact and attempt to explain it by applying existing theories, models, and mechanisms, or by inventing new ones. Second, they may reject the stylized fact, to argue that it is outright wrong. And finally, they may suggest that the stylized fact fails to capture the most important aspects of the world and needs to be amended, expanded, or ignored. Each of these steps merits further investigation through careful comparison of historical cases.

The study of the production and circulation of stylized facts may be useful for three interrelated fields. For philosophers of social science, stylized facts are a potential site for understanding how social scientists, especially non-experimental quantitative social scientists, practically manage the intractable dichotomies of fact and value, theory and data, positive and normative.

Second, and relatedly, stylized facts may help to flesh out the vocabulary of the sociology of social science. Guggenheim and Krause (2012) argue that the social sciences, to varying degrees, rely on model systems to generate knowledge, but they note that the more quantitative parts of sociology do not seem as reliant on model systems, instead emphasizing the generalizability of random samples to entire populations. It is just these efforts that seem most likely to generate stylized facts. Although it is possible to imagine stylized facts rooted in the analysis of model system, there seems to be a strong affinity between quantitative research and the production of stylized facts. Stylized facts thus help to complete our picture of the relationship between data and theory in different subfields of the social sciences.

Finally, for sociologists and political scientists interested in the role of experts and theories in policymaking, stylized facts offer an alternative entry point in the perennial quest to identify the influence of "ideas." Stylized facts do not stay inside the bounds of academic discourse. As in the examples above, even lightly theorized regularities can do profound political work, both overt and technical (being cited in a legal brief, as in the Regnerus case) and more diffuse (reshaping how the public imagines class divisions, as in the "top 1\%"). By explicitly theorizing stylized facts as an important kind of social scientific production, we can improve our ability to trace how social science influences, or fails to influence, policy. 


\section{Notes}

1 This is a central finding of the literature on the "democratic peace." For a recent review, see Kinsella 2005.

2 This claim, both highly disputed and widely taught, is the premise of the literature on "demographic transition." See Kirk 1996; Merchant 2015.

3 This claim derives, at some remove, from the work of Kinsey (Michaels 2013).

4 This finding is most prominently associated with the work of Piketty and Saez (2003). See section six below for an extended discussion of this and the next two examples.

5 This is the now infamous claim of Reinhart and Rogo (2010) of a "threshold" for debt above which economic growth stalls.

6 This is the "no differences" claim disputed by Regnerus (2012) in a highly controversial paper.

7 Following Luker (2008), "canonical" refers to social science research interested in the distribution of a population among known categories, drawing on a logic of verification more than a logic of discovery and emphasizing careful attention to issues of sampling, operationalization, and generalizability. In sociology, canonical social science is closely associated with quantitative methodologies, but the two are not equivalent (there exists canonical qualitative and historical research and non-canonical quantitative research).

8 See Ginther and Pollak 2004 for a similar definition of stylized facts.

9 Matthews (1959) contains the only published usage of the term that I have found that predates Kaldor (1961), but Matthews himself cites Kaldor for the term: "Neither type of model is therefore inconsistent with what Mr. Kaldor has called the 'stylised facts' of economic growth, and more refined tests need to be applied to discriminate between them" (Matthews 1959:764).

10 For these purposes, I end my analysis in 2008, as JStor's database has much smaller coverage for recent years.

$115110 / 394,416 \approx 1.3 \%$.

$12193 / 284,185 \approx 0.07 \%$.

13 Hacking's understanding of phenomena is not the only one available in the philosophy of science. In many ways, stylized facts come closer to the definition of phenomena put forward by Bogen and Woodward (1988). Bogen and Woodward (1988) attempt to distinguish phenomena from data and argue that scientific theories intend to explain phenomena rather than specific data points. Data provide evidence for the existence of phenomena, but always somewhat murkily, as subsidiary issues like measurement error obscure the clean link between the theoretical phenomena of interest and the actual observations (much as Kaldor argued that stylized facts allow for theorizing without attending to peculiar outliers). For Bogen and Woodward, as for Hacking in his discussion of phenomena, the context is the natural sciences, and thus definitional issues and the possibility of phenomena changing are not discussed.

14 This section draws heavily on Hirschman (2016), which includes a more detailed history of debates in economics over income inequality and top incomes in particular.

15 One early set of criticisms and rejoinders was published in Social Science Research in the November 2012 issue.

16 Perrin (2012), later coauthor of a peer-reviewed study critical of Regnerus.

17 http://www.asanet.org/press/asa_files_amicus_brief_in_same-sex_marriage_cases . $\mathrm{cfm}$ 


\section{References}

Abend, Gabriel. 2008. "The Meaning of 'Theory'." Sociological Theory 26(2):173-99. http: //dx.doi.org/10.1111/j.1467-9558.2008.00324.x

Ahluwalia, Montek S. 1976. "Income Distribution and Development: Some Stylized Facts." American Economic Review 66(2):128-35.

Atkinson, A. B. 1997. "Bringing Income Distribution in From the Cold." The Economic Journal 107(441):297-321. http://dx.doi.org/10.1111/j.0013-0133.1997.159.x

Bendor, Jonathan. 2003. "Herbert A. Simon: Political Scientist." Annual Review of Political Science 6(1):433-71. http://dx.doi .org/10.1146/annurev . polisci.6.121901.085659

Blyth, Mark. 2013. Austerity: The History of a Dangerous Idea.

Bogen, James, and James Woodward. 1988. "Saving the Phenomena." The Philosophical Review 97(3):303-52. http://dx.doi.org/10.2307/2185445

Burkhauser, Richard V., Shuaizhang Feng, Stephen P. Jenkins, and Jeff Larrimore. 2011. "Recent Trends in Top Income Shares in the United States: Reconciling Estimates from March CPS and IRS Tax Return Data." Review of Economics and Statistics 94(2):371-88. http://dx.doi.org/10.1162/REST_a_00200

Dube, Arindrajit. 2013. "A Note on Debt, Growth and Causality." University of Massachusetts Amherst.

Durkheim, Mile. 1997. Suicide: A Study in Sociology. New York: Free Press.

Elliott, Kevin C. 2013. "Selective Ignorance and Agricultural Research." Science, Technology E Human Values 38(3):328-50. http://dx . doi .org/10.1177/0162243912442399

Elsby, Michael WL, Bart Hobijn, and Aysegul Sahin. 2013. "The decline of the US labor share." Brookings Papers on Economic Activity. Issue 2:1-63.

Fernholz, Tim. 2013. "How influential was the Rogoff-Reinhart study warning that high debt kills growth?" qz.com.

Ginther, Donna K., and Robert A. Pollak. 2004. "Family structure and children's educational outcomes: Blended families, stylized facts, and descriptive regressions." Demography 41(4):671-96. http://dx.doi.org/10.1353/dem.2004.0031

Goldthorpe, John H. 2001. "Causation, Statistics, and Sociology." European Sociological Review 17(1):1-20. http://dx.doi.org/10.1093/esr/17.1.1

Gorski, Philip S. 2013. "Beyond the Fact/Value Distinction: Ethical Naturalism and the Social Sciences." Society 50(6):543-53. http://dx. doi .org/10.1007/s12115-013-9709-2

Guggenheim, Michael, and Monika Krause. 2012. "How facts travel: The model systems of sociology." Poetics 40(2):10117. http://dx.doi.org/10.1016/j . poetic. 2012.02.007

Hacker, J. S., and P. Pierson. 2010. “Winner-Take-All Politics: Public Policy, Political Organization, and the Precipitous Rise of Top Incomes in the United States." Politics \& Society 38(2):152. http://dx.doi.org/10.1177/0032329210365042

Hacking, Ian. 1983. Representing and Intervening. Cambridge University Press. http://dx . doi.org/10.1017/CB09780511814563

Hacking, Ian. 2000. The Social Construction of What? Harvard University Press.

Hacking, Ian. 2007. "Kinds of people: moving targets." Proceedings of the British Academy 151: 285-318. http://dx.doi.org/10.5871/bacad/9780197264249.003.0010

Hall, Peter A. 1989. The Political Power of Economic Ideas: Keynesianism across Nations. Princeton University Press. 
Hedstrom, Peter, and Petri Ylikoski. 2010. "Causal Mechanisms in the Social Sciences." Annual Review of Sociology 36(1):49-67. http: //dx. doi .org/10.1146/annurev . soc . 012809. 102632

Herndon, Thomas, Michael Ash, and Robert Pollin. 2013. “Does High Public Debt Consistently Stifle Economic Growth? A Critique of Reinhart and Rogoff." University of Massachusetts Amherst.

Hirschman, Daniel. 2016. "Inventing the Economy (Or, How We Learned to Stop Worrying and Love the GDP)." PhD dissertation, Department of Sociology, University of Michigan.

Hirschman, Daniel, and Isaac Ariail Reed. 2014. "Formation Stories and Causality in Sociology." Sociological Theory 32(4):259-82. http://dx . doi .org/10.1177/0735275114558632

Hout, Michael. 2012. "Social and Economic Returns to College Education in the United States." Annual Review of Sociology 38(1):379-400 http://dx . doi .org/10.1146/annurev . soc.012809.102503

Kaldor, Nicholas. 1957. "A Model of Economic Growth." The Economic Journal 67(268):591624. http://dx.doi.org/10.2307/2227704

Kaldor, Nicholas. 1961. Capital Accumulation and Economic Growth. Macmillan. http: //dx.doi.org/10.1007/978-1-349-08452-4_10

Kimball, Miles, and Yichaun Wang. 2013. “Economists looked even closer at Reinhart and Rogoff's data-and the results might surprise you." qz. com, June 12.

Kingdon, John W. 2002. Agendas, Alternatives, and Public Policies. 2nd ed. Longman.

Kinsella, David. 2005. "No Rest for the Democratic Peace." American Political Science Review 99(03):453-57. http://dx.doi.org/10.1017/s0003055405051774

Kirk, Dudley. 1996. "Demographic Transition Theory." Population Studies 50(3):361-87. http://dx.doi.org/10.1080/0032472031000149536

Krippner, Greta R. 2011. Capitalizing on Crisis: The Political Origins of the Rise of Finance. Harvard University Press.

Krugman, Paul. 2002. "For Richer." The New York Times Magazine, October 20.

Kuhn, Thomas S. 1969. The Structure of Scientific Revolutions. The University of Chicago Press.

Leifer, Eric M. 1992. "Denying the data: Learning from the accomplished sciences." Sociological Forum 7(2):283-99. http://dx.doi.org/10.1007/BF01125044

Luker, Kristin. 2008. Salsa Dancing into the Social Sciences: Research in an Age of Info-glut. Harvard University Press.

March, James, and Herbert A. Simon. 1958. Organizations. New York: John Wiley and Sons.

Matthews, R. C. O. 1959. "Duesenberry on Growth and Fluctuations." The Economic Journal 69(276):749-65. http://dx.doi.org/10.2307/2227671

Merchant, Emily. 2015. "Prediction and Control: Global Population, Population Science, and Population Politics in the Twentieth Century." PhD dissertation, Department of History, University of Michigan.

Michaels, Stuart. 2013. "The History of 10 Percent: Kinsey, Harry Hay, Social Science Measurement and the Politics of Gay Identity." University of Michigan.

Milgrom, Paul, and John Roberts. 1988. "An Economic Approach to Influence Activities in Organizations." American Journal of Sociology 94:S154-S179. http://dx . doi .org/10. $1086 / 228945$

Morgan, Mary S. 2012. The World in the Model: How Economists Work and Think. Cambridge University Press. http://dx.doi.org/10.1017/CB09781139026185 
Morris, Martina, and Bruce Western. 1999. "Inequality in Earnings at the Close of the Twentieth Century." Annual Review of Sociology 25:623-57. http://dx . doi .org/10.1146/ annurev.soc.25.1.623

Osborne, Cynthia. 2012. "Further comments on the papers by Marks and Regnerus." Social Science Research 41(4):779-83. http: //dx . doi .org/10.1016/j . ssresearch.2012 . 05. 002

Perrin, Andrew J. 2012. "bad science not about same-sex parenting." scatterplot. Available at http://scatter.wordpress.com/2012/06/23/ bad-science-not-about-same-sex-parenting/.

Perrin, Andrew J., Philip N. Cohen, and Neal Caren. 2013. "Are Children of Parents Who Had Same-Sex Relationships Disadvantaged? A scientific evaluation of the nodifferences hypothesis." Journal of Gay E Lesbian Mental Health 17(3):327-336. http: //dx.doi.org/10.1080/19359705.2013.772553

Piketty, Thomas, and Emmanuel Saez. 2003. "Income Inequality in the United States, 19131998." The Quarterly Journal of Economics 118(1):1-41. http://dx.doi.org/10.1162/ 00335530360535135

Proctor, Robert, and Londa Schiebinger, eds. 2008. Agnotology: The Making and Unmaking of Ignorance. Stanford University Press.

Putnam, Hilary. 2002. The Collapse of the Fact/Value Dichotomy and Other Essays. Cambridge, MA: Harvard University Press.

Reed, Isaac. 2008. "Maximal interpretation in Clifford Geertz and the strong program in cultural sociology: Towards a new epistemology." Cultural Sociology 2(2):187-200. http://dx.doi.org/10.1177/1749975508091032

Reed, Isaac Ariail. 2011. Interpretation and Social Knowledge. University Of Chicago Press. http://dx.doi.org/10.7208/chicago/9780226706726.001.0001

Regnerus, Mark. 2012. "How different are the adult children of parents who have same-sex relationships? Findings from the New Family Structures Study." Social Science Research 41(4):752-70. http://dx.doi.org/10.1016/j.ssresearch.2012.03.009

Reinhart, Carmen M., and Kenneth S. Rogoff. 2010. "Growth in a Time of Debt." American Economic Review 100(2):573-78. http://dx.doi.org/10.1257/aer.100.2.573

Reinhart, Carmen M., and Kenneth S. Rogoff. 2011. “Too Much Debt Means the Economy Can't Grow." Bloomberg View, July 14. http: //www. bloomberg. com/news/2011-07-14/ too-much-debt-means-economy-can-t-grow-commentary-by-reinhart-and-rogoff . html

Reynolds, A. 2007. "Has US Income Inequality Really Increased?" Cato Institute Policy Analysis Series (586).

Stone, Deborah A. 1989. "Causal Stories and the Formation of Policy Agendas." Political Science Quarterly 104(2):281-300. http://dx . doi .org/10.2307/2151585

Tienda, Marta, Katharine M. Donato, and Hector Cordero-Guzmán. 1992. "Schooling, Color, and the Labor Force Activity of Women." Social Forces 71(2):365-95. http://dx. doi .org/ $10.1093 / \mathrm{sf} / 71.2 .365$

Weber, Max. 2001. The Protestant Ethic and the Spirit of Capitalism. London: Routledge. 
Acknowledgements: I thank Beth Berman, Jamie Budnick, Wendy Espeland, Isaac Reed, and audiences at the 2013 Junior Theorists Symposium and the Michigan Social Theory Workshop for helpful comments on earlier drafts of this manuscript.

Daniel Hirschman: Department of Sociology, Brown University.

E-mail: daniel_hirschman@brown.edu. 